\title{
Factors influencing the survival of patients with testicular teratoma
}

\author{
JOAN M ALDERDICE, ${ }^{*}$ JD MERRETT $\dagger$ \\ From the *Department of Histopathology, The Laboratories, Belfast City Hospital, Belfast, and the \\ †Department of Medical Computing and Statistics, Institute of Clinical Science, Belfast
}

SUMMARY The histology of 51 cases of testicular teratoma, with or without seminoma, was reviewed and classified according to the World Health Organisation criteria. Full pathological and clinical details were obtained, and patients were followed up for periods varying from one to 10 years from orchidectomy. Multiple factors were studied in order to discover which affected prognosis. The pathological stage of the tumour proved to be the most important indicator. The previously described poor prognosis associated with yolk sac tumour was not confirmed.

Testicular teratomas traditionally carry a poor prognosis. As long ago as 1763 it was known that orchidectomy alone could produce an occasional cure, ${ }^{\prime}$ but when the results of treatment were first examined in detail in $1906^{2}$ it was found that few people were completely cured by surgery, with less than $15 \%$ of patients surviving five years. Pugh, whose calculations were based on 553 patients with teratoma between 1958 and 1967, found a five year corrected survival rate of $45 \%$. The incidence of this uncommon tumour has gradually increased over the past few decades, the highest rate (four to five per 100000 ) occurring in northern Europe and in Maoris in New Zealand. With the rise in incidence have come advances in staging procedures, the development of specific tumour markers, and effective chemotherapy. In this study we focused on the pathological and clinical factors present at the time of diagnosis to discover those which indicate a poor prognosis.

\section{Material and methods}

\section{PATIENTS}

All cases diagnosed as testicular teratoma, with or without seminoma, in the histopathology department of the Belfast City Hospital between.January 1974 and April 1983 were reviewed. Clinical and follow up information were obtained from the hospital records for periods varying from one to 10 years. Two patients had to be eliminated from the study because of inadequate follow up, which left a final

Accepted for publication 21 February 1985 number of 51 cases. All but five of the patients were referred to the Northern Ireland Centre for Radiotherapy and Oncology, which resulted in a uniformity in assessment and treatment. Those with localised disease received radiotherapy only, but most patients required several courses of chemotherapy which, for about the last five years, consisted of the Einhorn regimen (cisplatin, bleomycin, and vinblastine). Of the remainder, three received chemotherapy in other centres, one was treated with radiotherapy at the department of oncology, Belfast City Hospital, and the last had a differentiated teratoma with no spread and required no further treatment.

\section{HISTOLOGY}

Tissue from each orchidectomy specimen was immediately fixed in $4 \%$ aqueous formaldehyde, secondarily fixed in Helly's solution, and embedded in paraffin wax. Sections were cut at $5 \mu \mathrm{m}$ and stained with haematoxylin and eosin and periodic acid Schiff, with and without diastase pretreatment. Sections were then cut at $3 \mu \mathrm{m}$ and stained for $\alpha$-fetoprotein and $\beta$-human chorionic gonadotrophin using an unlabelled antibody peroxidaseantiperoxidase technique. Deparaffinised, rehydrated sections were treated with methanol and hydrogen peroxide to block endogenous peroxidase activity. Primary antibodies (rabbit), bridging antibody (swine), and peroxidase-antiperoxidase (rabbit) were obtained commercially (Dakopatts).

\section{CLASSIFICATION}

The histopathology was classified according to the 
World Health Organisation criteria, ${ }^{4}$ quoting also the modified classification of the British Testicular Tumour Panel. ${ }^{3 b}$ The former classification permitted subdivision into the many histopathological patterns encountered in teratomas and thus allowed more specific diagnosis by detailing each type (particularly yolk sac elements).

The following guidelines were used for diagnosis: 1 Teratoma. Tumours in this group are composed of several types of tissue representing different germinal layers (endoderm, mesoderm, and ectoderm). ${ }^{4}$ The process of differentiation is so complete that no histologically malignant areas can be found (with rare exceptions $s^{4}$ ), though some of the tissues may be immature..$^{3 \mathrm{~b}}$ Pugh classifies this type of tumour as teratoma differentiated (TD).

2 Teratocarcinoma. Tumours in this group contain both differentiated and undoubtedly malignant areas and can be thought of as a combination of teratoma and embryonal carcinoma. The malignant areas are usually epithelial or epithelial and mesenchymal. Pugh classifies these tumours as malignant teratoma intermediate (MTI).

3 Embryonal carcinoma. In these tumours there is an absence of organoid areas and differentiated structures. The cells are of primitive epithelial appearance, often with clear cytoplasm, growing in acinar, tubular, papillary, or solid patterns. ${ }^{4}$ Pugh would classify these tumours as malignant teratoma undifferentiated (MTU).

4 Yolk sac tumour. Yolk sac (endodermal sinus) tumour is characterised by cells of primitive appearance, growing typically in a loose, vacuolated network. Reticular, tubular, papillary, and solid patterns may be present. ${ }^{4}$ The tumour contains varying amounts of mucin, glycogen, and fat, and both intracellular and extracellular periodic acid Schiff positive hyaline globules may be seen. Pugh does not recognise this tumour as a separate entity in adults and would classify it as malignant teratoma undifferentiated (MTU).

5 Choriocarcinoma. This tumour is composed of elements identical to syncytiotrophoblast and cyto- trophoblast. There is no definite villus formation of placental type-that is, with stromal coresalthough villus like structures with syncytiotrophoblast surrounding masses of cytotrophoblast are sometimes seen, particularly at the advancing edge of the tumour. ${ }^{4}$ Pugh, on the other hand, maintains that the cells must be arranged in a definite papillary pattern and would classify tumours containing choriocarcinoma as malignant teratoma trophoblastic (MTT).

\section{STATISTICS}

Life tables were constructed to calculate median survival times for the various groups. Comparisons of survivals between the subgroups of patients were made using the Lee Desu statistic and confirmed by the log rank test. The conventional level of significance $(p<0.05)$ was used throughout.

\section{Results}

\section{HISTOPATHOLOGY}

The following patterns were encountered in the 51 cases: teratoma (TD), teratocarcinoma, embryonal carcinoma, yolk sac tumour, and choriocarcinoma, with or without seminoma. Most tumours (43) were of more than one histological type, the commonest combinations being teratocarcinoma with yolk sac and embryonal carcinoma with yolk sac. The remainder consisted of four pure embryonal carcinomas, three teratomas, and one pure yolk sac tumour. The overall median survival time was 33.7 months. The results are summarised in Table 1 .

Only four tumours were classified as teratoma (TD), and one of these also contained seminoma. Three patients are still living after 13,48 , and 119 months, but the other died seven months after orchidectomy. The numbers in this group were too small for statistical analysis.

Only five tumours contained choriocarcinoma, and in these a frequent close association with yolk sac tumour was seen; both being types of extraembryonic differentiation. Only one patient is still liv-

Table 1 Median survival times for each histopathological subtype in 51 patients with testicular teratoma

\begin{tabular}{|c|c|c|c|c|}
\hline \multirow{2}{*}{$\frac{\text { Histopathology }}{\text { Teratoma (TD) }}$} & \multicolumn{2}{|c|}{ No of cases (\%) } & \multirow{2}{*}{$\frac{\text { Median survival time (mo) }}{*}$} & \multirow{2}{*}{ p } \\
\hline & $\begin{array}{l}\text { With } \\
\text { Without }\end{array}$ & $\begin{array}{r}4(8) \\
47(92)\end{array}$ & & \\
\hline Teratocarcinoma & $\begin{array}{l}\text { With } \\
\text { Without }\end{array}$ & $\begin{array}{l}31(61) \\
20(39)\end{array}$ & $\begin{array}{l}35.6 \\
31 \cdot 3\end{array}$ & 0.19 \\
\hline Embryonal carcinoma & $\begin{array}{l}\text { With } \\
\text { Without }\end{array}$ & $\begin{array}{l}15(29) \\
36(71)\end{array}$ & $\begin{array}{l}25 \cdot 2 \\
52 \cdot 9\end{array}$ & $0.04 \dagger$ \\
\hline Yolk sac tumour & $\begin{array}{l}\text { With } \\
\text { Without }\end{array}$ & $\begin{array}{l}37(72) \\
14(28)\end{array}$ & $\begin{array}{r}29.6 \\
>108.0\end{array}$ & 0.55 \\
\hline Choriocarcinoma & $\begin{array}{l}\text { With } \\
\text { Without }\end{array}$ & $\begin{array}{r}5(10) \\
46(90)\end{array}$ & $*$ & $*$ \\
\hline
\end{tabular}

*Numbers too small for statistical analysis.

†Significant difference. 
ing 22 months after orchidectomy; the other four died three, four, seven and 10 months after orchidectomy. Again, because of the small number in this group, statistical analysis was not performed.

\section{SIDE}

One patient had bilateral tumours. At the age of 26 he developed a right sided seminoma, and when he was 34 he presented with a left sided combined tumour with seminoma, teratocarcinoma, and yolk sac elements. Table 2 shows the difference in survival between those with right and left sided tumours.

\section{CRYPTORCHIDISM}

Two patients $(3.9 \%)$ in this series had a history of testicular maldescent. One had an incompletely descended right testis, which had descended three months before presentation and contained a tumour weighing $250 \mathrm{~g}$. Histology showed a pure yolk sac tumour. The other patient had had a right orchidopexy at the age of 9 , and presented with a right sided combined tumour (teratocarcinoma and yolk sac and seminoma) when aged 37 .

\section{FAMILY HISTORY}

Three patients $(5.9 \%)$ had a family history of a brother with a testicular tumour. One of these patients, who had a teratocarcinoma, had an identical twin with a seminoma.

\section{AGE AT ORCHIDECTOMY}

Patients' ages ranged from 15 years to 56 years, with a mean of 29.8 years (SD 9.2). Patients with combined teratoma and seminoma were significantly older $(p=0.04)$ than those with teratomatous ele- ments only. No other histological subgroup showed a significant age preference, but the small number of patients with differentiated teratoma (mean age 24 years) and choriocarcinoma (mean age 23.6 years) tended to be in the younger age group.

\section{DURATION OF SYMPTOMS BEFORE}

\section{ORCHIDECTOMY}

The duration of symptoms before orchidectomy was known in 49 patients and varied from 10 days to three years. Fifty five percent had symptoms for two months or less (Table 2).

\section{PATHOLOGICAL STAGE}

In pathological stage one (P1) the tumour is confined to the rete and body of testis, in the second stage (P2) it has spread into the epididymis and lower cord, and in P3 it extends to the upper cord. Table 2 shows that the difference in survival between those classified as P1 and those as P2 and P3 is highly significant. Furthermore, the differences in survival of the two groups persisted when stratified for each of several other factors, including metastases at presentation, embryonal carcinoma, and duration of symptoms.

\section{WEIGHT OF ORCHIDECTOMY SPECIMEN}

The normal testis weighs between $10.5 \mathrm{~g}$ and $14 \mathrm{~g}$. Orchidectomy specimens consisted of testis and cord and ranged from $25 \mathrm{~g}$ to $880 \mathrm{~g}$ (mean $182 \mathrm{~g}$ ). Information was available in 48 cases (Table 2).

\section{METASTASES AT PRESENTATION}

Information about metastases at presentation was available in 49 patients. Secondary spread was most

Table 2 Median survival times for each clinical and pathological factor studied in patients with testicular teratoma

\begin{tabular}{|c|c|c|c|}
\hline Clinical/pathological factors & No of cases (\%) & Median survival time (mo) & $p$ \\
\hline $\begin{array}{l}\text { Side } \\
\text { Right } \\
\text { Left }\end{array}$ & $\begin{array}{l}34(66 \cdot 6) \\
17(33 \cdot 3)\end{array}$ & $\begin{array}{l}46 \cdot 7 \\
21 \cdot 0\end{array}$ & $0 \cdot 13$ \\
\hline $\begin{array}{l}\text { Duration of symptoms } \\
\leqslant 2 \text { months } \\
>2 \text { months }\end{array}$ & $\begin{array}{l}27(55 \cdot 1) \\
22(44 \cdot 9)\end{array}$ & $\begin{array}{l}36 \cdot 7 \\
30 \cdot 0\end{array}$ & 0.89 \\
\hline $\begin{array}{l}\text { Pathological stage } \\
\text { P1 } \\
\text { P2 }+ \text { P3 } \\
\text { Weight of orchidectomy }\end{array}$ & $\begin{array}{l}31(60 \cdot 8) \\
20(39 \cdot 2)\end{array}$ & $\begin{array}{l}71 \cdot 4 \\
11 \cdot 7\end{array}$ & $0.002^{*}$ \\
\hline $\begin{array}{l}<120 \mathrm{~g} \\
>120 \mathrm{~g}\end{array}$ & $\begin{array}{l}24(50 \cdot 0) \\
24(50 \cdot 0)\end{array}$ & $\begin{array}{l}47 \cdot 2 \\
22 \cdot 8\end{array}$ & 0.12 \\
\hline $\begin{array}{l}\text { Metastases at presentation } \\
\text { Without } \\
\text { With }\end{array}$ & $\begin{array}{l}16(32 \cdot 7) \\
33(67 \cdot 3)\end{array}$ & $\begin{array}{r}>108.0 \\
27.7\end{array}$ & $0.03^{*}$ \\
\hline $\begin{array}{l}\alpha \text {-Fetoprotein }(\mathrm{kU} / \mathrm{l}) \\
\quad<100 \\
\geqslant 100 \\
\beta \text {-Human chorionic gonadotrophin }(\mathrm{IU} / \mathrm{l})\end{array}$ & $\begin{array}{l}14(46 \cdot 7) \\
16(53 \cdot 3)\end{array}$ & $\begin{array}{l}65 \cdot 1 \\
28 \cdot 0\end{array}$ & 0.45 \\
\hline $\begin{array}{l}\text { Normal } \\
\text { Raised }\end{array}$ & $\begin{array}{l}16(55 \cdot 2) \\
13(44 \cdot 8)\end{array}$ & $\begin{array}{l}55 \cdot 6 \\
22 \cdot 0\end{array}$ & $0 \cdot 16$ \\
\hline
\end{tabular}

*Significant difference. 
commonly found in abdominal and pelvic lymph nodes, then in the lungs, and the third most common site was supraclavicular nodes. The liver was affected in two patients. The difference in survival between those with and without metastases at presentation was significant (Table 2). When stratified for pathological stage, however, the difference failed to reach significance $(p=0 \cdot 12)$.

\section{INCREASED CONCENTRATIONS OF TUMOUR}

\section{MARKERS}

The serum concentration of $\alpha$-fetoprotein taken either before operation or immediately afterwards was recorded in only 31 of 51 cases. Values ranged from normal $(<17 \mathrm{kU} / \mathrm{l})$ in nine patients to $7000 \mathrm{kU} / \mathrm{l}$ in one patient, who is still alive 28 months after orchidectomy (Table 2).

The serum concentration of $\beta$-human chorionic gonadotrophin taken either before operation or immediately afterwards was recorded in only 29 of 51 cases. Values ranged from normal $(<1 \mathrm{IU} / \mathrm{l})$ in 16 patients to $399400 \mathrm{IU} / 1$ in a patient with choriocarcinoma, who died 10 months after orchidectomy (Table 2).

\section{Discussion}

Although no histologically malignant areas could be found in those tumours diagnosed as teratoma (TD), one of the four patients died seven months after orchidectomy; this equals the $25 \%$ mortality quoted by $\mathrm{Pugh}^{3 \mathrm{a}}$ in his series. These are most disquieting neoplasms and the histopathologist is often left with the uneasy feeling that more extensive sectioning might show obviously malignant areas. ${ }^{3 a}$ This diagnosis, however, carries the most favourable prognosis.

Of the four other histological subtypes, embryonal carcinoma was the only one which was associated statistically with poor survival $(p=0 \cdot 04)$. Those with choriocarcinoma had a high mortality, but unfortunately the numbers were too small for statistical analysis.

Yolk sac elements were present in $72 \%$ of tumours in this series. This varied from a single microscopic focus in several cases to one pure yolk sac tumour. The median survival time of patients with yolk sac elements was much lower than those without (Table 1), but the difference was not statistically significant. Other researchers into germ cell tumours have had different results. Talerman, ${ }^{5}$ in both retrospective and prospective studies, agreed that yolk sac elements were relatively common in adult testicular germ cell neoplasms (which explained the frequent increase in $\alpha$-fetoprotein concentration), but found that the prognosis for adults with testicu- lar tumours containing yolk sac elements was unfavourable. A study by Parkinson and Beilby ${ }^{6}$ two years later found that pure yolk sac tumours proved highly malignant and that in mixed germ cell tumours the malignant nature of the yolk sac component was maintained even when combined with somatic elements; but when seminoma was also present the survival rate improved significantly. This series showed no significant difference in median survival time between those with yolk sac elements and those without (Table 1). The one patient with a pure yolk sac tumour was alive and well at the end of follow up, 19 months after orchidectomy. This series also differed from that of Parkinson and Beilby in that there was no improvement in the survival of patients with yolk sac tumour when seminoma was present.

One possible problem in the statistical analysis of tumours with yolk sac is that a tumour with a single microscopic focus and a pure yolk sac tumour count equally as tumours with yolk sac. Further quantitative subdivision to show the effect of this component more accurately was not possible because of the small numbers.

The 51 patients in this series had a 2:1 right sided predominance, rather greater than the 5:4 ratio quoted by Pugh. ${ }^{3 a}$ The poorer survival of patients with left sided tumours is an unexpected finding. The reason for it, though rather obscure, may be related to differing venous and lymphatic drainage on the two sides.

Maldescent of the testis occurs in $0.77 \%$ of one year old boys.' A history of testicular maldescent was noted in two patients in this series $(3.9 \%)$, and the real value is possibly higher as the question of cryptorchidism was often not raised in the history and not recorded in the clinical notes. This shows that those with a history of cryptorchidism have a greater than normal risk of malignancy, but the vast majority of tumours arise in normally descended testes.

The pathological stage of the tumour has proved to be the most important prognostic indicator. The pathological stage is a measure of the local spread of a tumour and is indirectly related to tumour histology. The less aggressive subtypes (teratoma and teratocarcinoma) mostly presented in the first pathological stage, while tumours with embryonal carcinoma and yolk sac elements showed a greater tendency to present in the second and third pathological stages. One would expect that duration of symptoms before orchidectomy and pathological stage would show a direct correlation and have a similar effect on prognosis; in the series, however, this did not prove to be true. Duration of symptoms was one of the least significant factors affecting sur- 


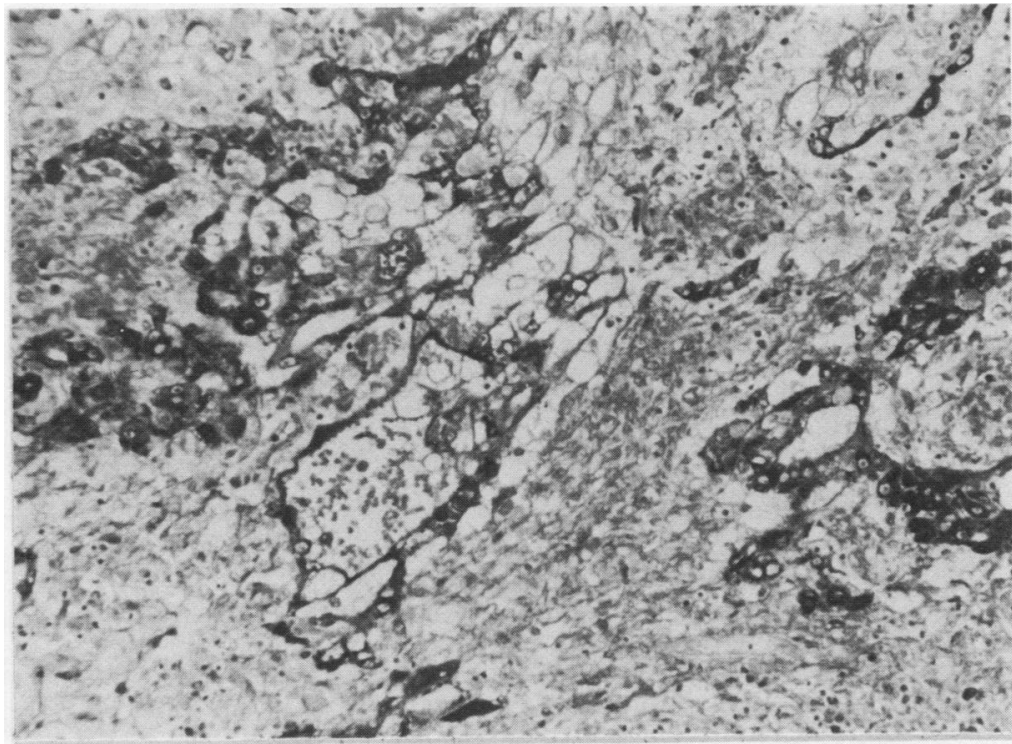

Fig. 1 Yolk sac elements stained for $\alpha$-fetoprotein. Positive staining around cystic spaces. Immunoperoxidase. $\times 120$.

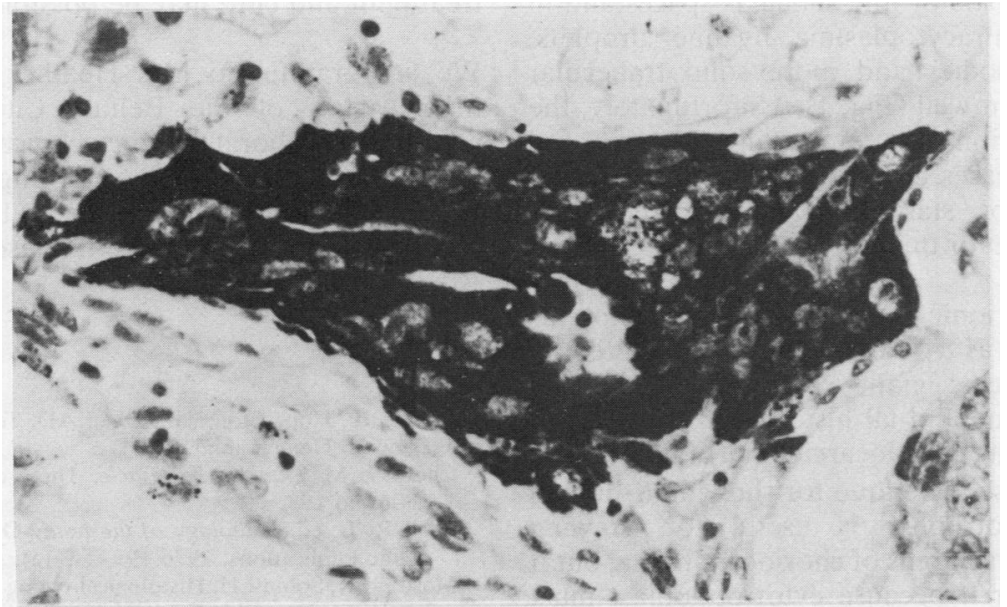

Fig. 2 Single syncytiotrophoblastic giant cell in yolk sac tumour, positive for human chorionic gonadotrophin. No associated cytotrophoblast.

Immunoperoxidase. $\times 380$.

vival. It seems that pathological and clinical stage at presentation are related more to how aggressive the neoplasm is than to how long it has been present. The presence of metastases, another measure of the stage of disease, also proved to be an important factor. Secondary spread was most often encountered in tumours containing embryonal carcinoma and yolk sac. Staging procedures such as chest radiograph, lymphogram, intravenous pyelogram, and abdominal ultrasound, with the addition in selected cases of computed tomograms of abdomen and lungs, should delineate those with no metastases and a fairly good prognosis from those with secondary spread and a poorer outlook.

Many recent studies ${ }^{89}$ have now linked the production of $\alpha$-fetoprotein with the presence of yolk sac elements within a tumour and shown that $\alpha$-fetoprotein is a useful marker for the presence of yolk sac. In yolk sac tumours the immunoperoxidase technique showed $\alpha$-fetoprotein mostly in the 


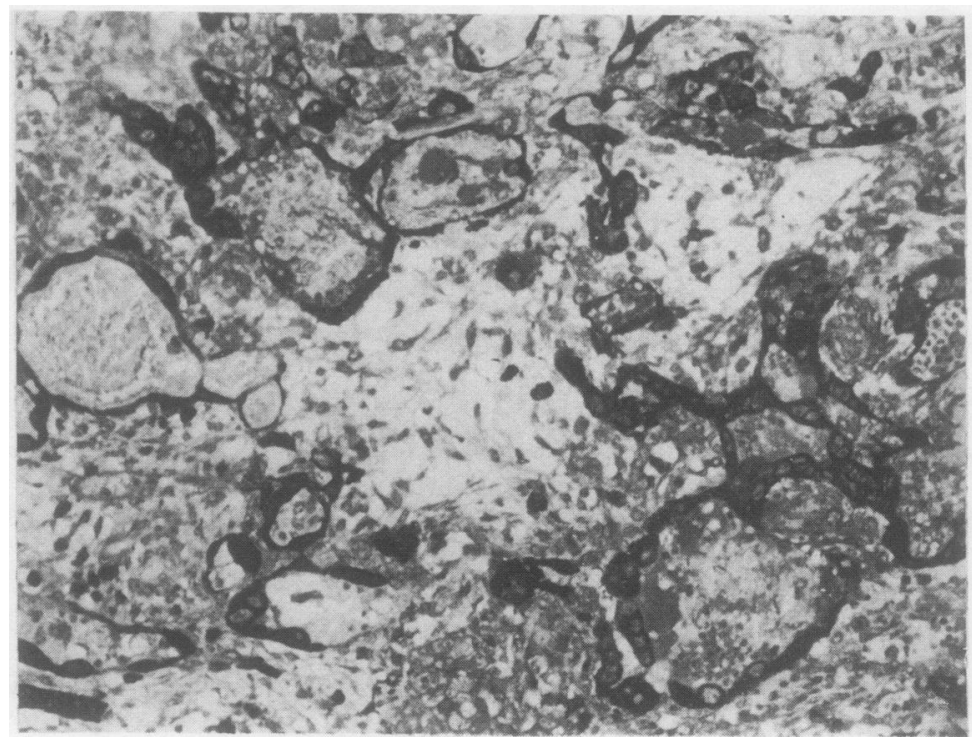

Fig. 3 Choriocarcinoma. Syncytiotrophoblast positive for human chorionic gonadotrophin and associated with cytotrophoblast. Immunoperoxidase. $\times 150$.

cells lining the cystic or fine reticular spaces and in the extra or intracytoplasmic hyaline droplets. Duval Schiller bodies and more solid trabecular areas did not stain well (Fig. 1). Unfortunately, the serum concentration of $\alpha$-fetoprotein was recorded in only $59 \%$ of cases and, as small numbers lower the sensitivity of statistical analysis, the nonsignificant $p$ value for this factor must be interpreted with caution.

$\beta$-human chorionic gonadotrophin is not as specific a marker as $\alpha$-fetoprotein. It is secreted by syncytiotrophoblastic giant cells, which may be found in seminoma and all histological subtypes of teratoma including choriocarcinoma (Fig. 2). The immunoperoxidase technique for showing $\beta$-human chorionic gonadotrophin is useful for drawing attention to possible areas of choriocarcinoma, but it is not specific for it because cytotrophoblast must also be present for the diagnosis to be made (Fig. 3). Considerably increased concentrations are, however, generally confined to cases of choriocarcinoma. The serum concentration of $\beta$-human chorionic gonadotrophin was recorded in only $57 \%$ of cases, and, although raised concentrations of this marker had a greater effect on survival than raised serum $\alpha$-fetoprotein, it did not reach statistical significance, once again because of small subgroups.

The results of the study suggest that the pathological and clinical staging of disease is of greater importance than histological typing and tumour markers. Preventive medicine incorporating education as to the significance of a lump in the scrotum and encouragement to present promptly would aid the diagnosis of malignancy at an early stage when treatment and cure may be possible.

We are grateful to Mrs Heather Foster and the MLSO staff of the Belfast City Hospital histopathology laboratory for technical assistance, and to Mrs Jacqueline Hamill for typing the manuscript. We also thank Dr D Hayes, Dr JD Biggart, and Dr S McMillan for advice on the manuscript and Dr DC Allen for photography.

\section{References}

' Blandy JP, Hope-Stone HF, Dyan AD. Tumours of the testicle. London: Heinemann, 1970:1.

${ }^{2}$ Chevassu M. Tumeurs du testicle. Thèse de Paris. G Steinheil, 1906: no 193.

${ }^{3}$ Pugh RCB, ed. Pathology of the testis. Oxford: Blackwell Scientific Publications, 1976: 199-243 (a); 144-6 (b)

${ }^{4}$ Mostofi FK, Sobin LH. Histological typing of testicular tumours. In: International histological classification of tumours, no 16. Geneva: World Health Organisation, 1977:27-31.

${ }^{5}$ Talerman A. The incidence of yolk-sac tumour (Endodermal sinus tumour) elements in germ cell tumours of the testis in adults. Cancer 1975;36:211-5.

- Parkinson C, Beilby JOW. Features of prognostic significance in testicular germ cell tumours. J Clin Pathol 1977;30:113-9.

' Scorer G. The descent of the testis. Arch Dis Child 1964;39:605-9.

* Tsushida Y, Saito S, Ishida M, et al. Yolk sac tumour and alphafetoprotein. A report of three cases. Cancer 1973;32:917-21.

${ }^{4}$ Norgaard-Pedersen B, Albrechtsen R, Teilum G. Serum alphafetoprotein as a marker for endodermal sinus tumour (yolk sac tumour) or a vitelline component of a teratocarcinoma. Acta Pathol Microbiol Scand (sect A). 1975;83:57389.

Requests for reprints to: Dr Joan M Alderdice, Department of Histopathology, The Laboratories, Belfast City Hospital, Belfast BT9 7AD, N. Ireland. 